\title{
SUPERAÇÃO DA DORMÊNCIA DAS SEMENTES DE Delonix regia (Bojer ex Hook.) Raf. ${ }^{1}$
}

\author{
Glauciana da Mata Ataíde², Elisa Monteze Bicalho ${ }^{3}$, Denise Cunha Fernandes dos Santos Dias ${ }^{4}$, Renato \\ Vinícius Oliveira Castro ${ }^{5}$ e Eveline Mantovani Alvarenga ${ }^{4}$
}

\begin{abstract}
RESUMO - Delonix regia (flamboyant) é uma espécie arbórea amplamente utilizada no Brasil, de alto valor ornamental. Sua propagação ocorre por meio de sementes, que apresentam dormência pela impermeabilidade do tegumento à água. Com o objetivo de determinar a melhor metodologia para a superação da dormência, as sementes da espécie foram submetidas a diferentes tratamentos: 1) imersão em água fervente por 1 min; 2) imersão em água a $80^{\circ} \mathrm{C}$ e a $90^{\circ} \mathrm{C}$ por 1 e $3 \mathrm{~min}$; 3) escarificação manual com lixa; e 4) imersão em ácido sulfúrico concentrado por 15, 30, 45 e 60 min, além da testemunha. Após cada tratamento, as sementes foram colocadas para germinar em rolo de papel, na temperatura de $25{ }^{\circ} \mathrm{C}$. Em uma segunda etapa, os tratamentos mais efetivos na quebra de dormência das sementes foram aplicados e a germinação, testada à temperatura de $30^{\circ} \mathrm{C}$. Em ambas as temperaturas, as contagens de germinação (plântulas normais) foram realizadas diariamente. O tratamento das sementes de flamboyant em água quente a $90{ }^{\circ} \mathrm{C}$ por $1 \mathrm{~min}$ foi o mais eficiente na promoção da germinação, sendo prático e dispensando o uso de tratamentos químicos. O teste de germinação realizado à temperatura de $30^{\circ} \mathrm{C}$ não forneceu resultados satisfatórios, com menores porcentagens de plântulas normais e IVG que os testes a $25^{\circ} \mathrm{C}$. Foram descritas como plântulas normais as que possuíam visíveis dois cotilédones semiabertos, hipocótilo alongado, raiz primária bem desenvolvida e raízes adventícias curtas. Conclui-se que sementes de Delonix regia germinam melhor a $25^{\circ} \mathrm{C}$ após a imersão por $1 \mathrm{~min}$ em água a $90^{\circ} \mathrm{C}$, sendo este indicado como tratamento para superação da dormência da espécie.
\end{abstract}

Palavras-chave: Flamboyant; Germinação; Temperatura.

\section{OVERCOMING SEED DORMANCY OF Delonix regia (Bojer ex Hook.) Raf.}

\begin{abstract}
Delonix regia (flamboyant) is a tree widely used in Brazil, highly valued as ornamental plant. Its propagation is by seed, which show dormancy caused by its integument, impermeable to water. With the objective of determining the best method to overcome dormancy in the laboratory, the seeds were submitted to different treatments: 1) immersion in boiling water for one minute, 2) immersion in water at $80^{\circ} \mathrm{C}$ and $90^{\circ} \mathrm{C}$ for one and three minutes, 3) scarification with sandpaper, and 4) immersion in concentrated sulfuric acid for 15, 30, 45 and 60 minutes, plus control with intact seeds. After each treatment, the seeds germinated in towel paper roll at a temperature of $25^{\circ} \mathrm{C}$. In a second step, the most effective treatments to overcome dormancy were applied and germination was evaluated at $30^{\circ} \mathrm{C}$. At both temperatures, germination counts (normal seedlings) were performed daily. The immersion of the seeds of flamboyant in hot water $\left(90^{\circ} \mathrm{C}\right.$ for one minute) was feasible and the most effective in promoting germination, eliminating the use of chemical treatments. Germination test performed at $30^{\circ} \mathrm{C}$ did not achieve satisfying results, with lower percentages of normal seedlings and PGI than the tests carried out at $25^{\circ} \mathrm{C}$. Normal seedlings were described as those with two visible half-open cotyledons, elongated hypocotyl, well developed primary root, and short adventitious roots. Delonix regia seeds germinate best at $25^{\circ} \mathrm{C}$ after 1-minute immersion in water at $90^{\circ} \mathrm{C}$, which is indicated as a treatment to overcome the dormancy of the species.
\end{abstract}

Keywords: Flamboyant; Germination; Temperature.

\footnotetext{
${ }^{1}$ Recebido em 12.03.2013 aceito para publicação em 06.11.2013.

${ }^{2}$ Instituto Federal de Educação, Ciência e Tecnologia do Sudeste de Minas Gerais, Campus Rio Pomba. E-mail: <glaucianadamata@yahoo.com.br>.

${ }^{3}$ Doutorado em Biologia Vegetal na Universidade Federal de Minas Gerais, UFMG. E-mail:<elisamtzebio@yahoo.com.br> .

${ }^{4}$ Departamento de Fitotecnia, Universidade Federal de Viçosa, UFV. E-mail:<dcdias@ufv.br> e <eveline@ufv.br>.

${ }^{5}$ Departamento de Engenharia Florestal, Universidade de Brasília, UNB. E-mail:<castrorvo@ymail.com>.
} 


\section{INTRODUÇÃO}

Delonix regia (Bojerex Hook.) Raf., conhecida popularmente como flamboyant, é uma espécie florestal exótica, oriunda de Madagascar e altamente adaptada às condições ambientais de clima tropical. A espécie está inserida na família Fabaceae, subfamília Caesalpinoideae, e tem sido utilizada na arborização de praças e ruas brasileiras (LUCENA et al., 2006). Sua dispersão ocorre por meio de sementes, que apresentam dormência causada pela impermeabilidade do tegumento à água.

A dormência é caracterizada pela suspensão temporária do crescimento visível de qualquer parte vegetal que contenha meristema (LANG, 1996). Segundo Lemos Filho et al. (1997), a dormência das sementes favorece a sobrevivência das plantas no ambiente, sendo estratégia vantajosa em locais onde as condições para seu desenvolvimento variam consideravelmente no tempo e no espaço. No entanto, constitui problema na propagação para fins de cultivo e produção de mudas, devido ao fato de a germinação das sementes ser lenta e desuniforme, ou muito reduzida.

Em sementes da família Leguminosae (Fabaceae), o tipo mais comum de dormência é a causada pela impermeabilidade do tegumento à água (POPINIGIS, 1985), estando presente em cerca de $85 \%$ das espécies dessa família (ROLSTON, 1978). A dureza do tegumento é atribuída à resistência à entrada de água promovida pela testa, que apresenta camada de células em paliçada, com paredes espessas e recobertas externamente por lignina (CARDOSO, 2004). O bloqueio físico causado por essas células impede as trocas gasosas e impossibilita a embebição das sementes e a oxigenação do embrião, que permanece latente (BECHARA et al., 2007).

Para superação desse tipo de dormência, são utilizados tratamentos como escarificação física, mecânica ou química, podendo ser por água quente (SMIDERLE et al., 2005; TURNER et al., 2005; ALVES et al., 2008), ácido sulfúrico (SANTARÉM; ÁQUILA, 1995; TELES al., 2000; MESCHEDE et al., 2004) ou abrasão (MALAVASI; MALAVASI, 2004; LUCENA et al., 2006; FERRARESI et al., 2009), antes da semeadura. Esses processos podem acelerar e aumentar a taxa de germinação de sementes de flamboyant, mas não foram encontrados estudos conclusivos a respeito de qual o melhor tratamento para a espécie.
Em estudos que envolvam a avaliação da germinação das sementes, a classificação correta das plântulas obtidas como normais ou anormais é fundamental para obtenção de resultados seguros que realmente expressem a porcentagem de germinação do lote. Nesse contexto, a descrição da morfologia das plântulas germinadas em laboratório é ferramenta imprescindível na padronização e condução dos testes de germinação, especialmente nas espécies que ainda não são descritas nas Regras para Análises de Sementes - RAS (BRASIL, 2009).

Dessa forma, o objetivo deste estudo foi determinar a metodologia mais adequada para superação da dormência de sementes de flamboyant (Delonix regia).

\section{MATERIAL E MÉTODOS}

Este trabalho foi conduzido no Laboratório de Análise de Sementes do Departamento de Fitotecnia da Universidade Federal de Viçosa (UFV). Sementes de Delonix regia foram coletadas de uma população natural da região de Visconde do Rio Branco, MG, composta por três a quatro árvores-matriz, em setembro de 2009. Após a coleta, as sementes foram beneficiadas e armazenadas em tambores de fibra, em câmara fria a $20^{\circ} \mathrm{C}$, no Laboratório de Sementes Florestais da UFV.

Para determinação da umidade das sementes, foi adotado o método da estufa a $105 \pm 3^{\circ} \mathrm{C}$ por $24 \mathrm{~h}$, conforme Brasil (2009). Foram utilizadas três repetições de 20 sementes, sendo os resultados expressos em porcentagem calculados com base no peso das sementes úmidas (base úmida).

As sementes foram submetidas a diferentes tratamentos para superação da dormência, os quais foram: Trat 1 - imersão em água fervente por $1 \mathrm{~min}$; Trat 2 - imersão em água a $80^{\circ} \mathrm{C}$, por 1 min; Trat 3 - imersão em água a $80^{\circ} \mathrm{C}$, por 3 min; Trat 4 - imersão em água a $90^{\circ} \mathrm{C}$, por $1 \mathrm{~min}$; Trat 5 - imersão em água a $90^{\circ} \mathrm{C}$, por $3 \mathrm{~min}$; Trat 6 - escarificação manual com lixa; Trat 7 - imersão em ácido sulfúrico concentrado por 15 min; Trat 8 - imersão em ácido sulfúrico concentrado por 30 min; Trat 8 - imersão em ácido sulfúrico concentrado por 45 min; e Trat 9 - imersão em ácido sulfúrico concentrado por $60 \mathrm{~min}$, além da testemunha (sementes intactas - Trat 0 ).

Nos tratamentos com água quente e fervente, 120 sementes foram imersas em $1 \mathrm{~L}$ de água nas temperaturas desejadas, sendo retirada a fonte de calor

Revista Árvore, Viçosa-MG, v.37, n.6, p.1145-1152, 2013

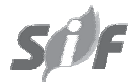


somente após o fim do período de imersão. A escarificação manual foi realizada com lixa número 80, no lado oposto ao eixo embrionário, até o rompimento da testa e exposição do cotilédone. Nas sementes tratadas com ácido sulfúrico, foram utilizados $80 \mathrm{~mL}$ de ácido em cada 120 sementes, sendo estas mantidas sob agitação constante durante os tempos desejados. Após a imersão, as sementes foram lavadas em água corrente, para eliminação do excesso de ácido.

Após a aplicação dos tratamentos, as sementes foram colocadas para germinar. Para tanto, quatro repetições de 25 sementes (tratadas com o fungicida Captan 0,5\% por 3 min, sob agitação constante) foram distribuídas sobre duas folhas de papel tipo germitest, umedecidas com quantidade de água equivalente a 2,5 vezes o peso do papel, sendo cobertas com uma folha. Foram confeccionados rolos que foram mantidos em germinador a $25^{\circ} \mathrm{C}$, sob luz constante. Foram feitas contagens diárias do número de sementes germinadas durante 21 dias, sendo consideradas germinadas as plântulas normais para cada repetição e tratamento. Consideraram-se como plântulas normais aquelas que apresentaram raiz primária bem desenvolvida, raízes secundárias curtas, hipocótilo alongado e cotilédones semiabertos, além das primeiras plúmulas visíveis. Ao final do período, foram avaliadas também a porcentagem de sementes duras, sementes mortas e plântulas anormais por tratamento.

Com base nesses resultados preliminares, realizou-se uma segunda etapa, na qual foi avaliado o efeito da temperatura constante de $30^{\circ} \mathrm{C}$ sobre a germinação da espécie, após a aplicação dos dois tratamentos que apresentaram melhor desempenho na superação da dormência. Nessa etapa, as sementes foram colocadas para germinar a $30^{\circ} \mathrm{C}$, conforme descrito anteriormente, sendo as avaliações feitas durante o período de 17 dias. Foram computadas as plântulas normais diariamente, utilizando-se o mesmo critério estabelecido na etapa anterior.

Foram calculados a porcentagem de germinação e o Índice de Velocidade de Germinação (IVG), utilizando-se a fórmula proposta por Maguire (1962): IVG $=\Sigma\left(n_{i} / t_{i}\right)$, em que $n_{i}$ é o número de sementes por dia e $t_{i}$, o tempo (dias).

O delineamento experimental utilizado foi o inteiramente casualizado (DIC). Os dados de germinação acumulada no tempo na temperatura de $25^{\circ} \mathrm{C}$ foram submetidos à análise de variância, e o desdobramento das frequências de cada tratamento foi realizado pelo ajuste de médias à função acumulativa de distribuição de Weibull (BROWN; MAYER, 1988). As porcentagens finais de plântulas normais e o IVG foram submetidos à análise de variância e as médias dos tratamentos, comparadas pelo teste de Tukey a 5\% de significância. Todas as análises foram feitas com o auxílio do software Statistica 8.0 (STATSOFT, 2008).

As plântulas normais e anormais de todos os tratamentos foram fotografadas e caracterizadas quanto às estruturas e anomalias presentes.

\section{RESULTADOS}

As sementes de flamboyant apresentaram grau de umidade em torno de 5,2\% no início dos testes, com variação de 0,3 ponto percentual entre as repetições. Esse baixo valor de umidade pode estar relacionado à imposição da dormência tegumentar, uma vez que o grau de umidade é um dos fatores determinantes desse tipo de dormência, em que o tegumento das sementes se torna progressivamente duro e impermeável à medida que o grau de umidade diminui (BEWLEY; BLACK, 1982).

A distribuição da porcentagem de germinação acumulada nos diferentes tratamentos foi ajustada com precisão pelo modelo de distribuição de Weibull (Figura 1). De acordo com esses resultados, verificou-se que a germinação das sementes submetidas aos tratamentos com água quente e escarificação manual com lixa iniciou-se a partir do sexto dia de avaliação do experimento, aumentando progressivamente até o $16^{\circ}$ dia após a semeadura, a partir do qual houve estabilização da curva. Nos tratamentos que utilizaram escarificação química e no controle, não foi observada germinação a partir do $12^{\circ}$ dia.

Pela Tabela 1, verifica-se que os tratamentos com ácido sulfúrico não foram eficientes para a superação da dormência de sementes de $D$. regia, uma vez que se observou, nesses tratamentos, maior porcentagem de sementes duras ao final do teste de germinação. Os quatro tempos de escarificação ácida testados não diferiram estatisticamente do controle, indicando que o uso do ácido provavelmente não alterou a permeabilidade do tegumento, contrastando com os resultados obtidos por Eira et al. (1993), Amaral et al. (1995) e Costa et al. (2010) em sementes de Enterolobium

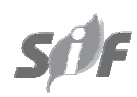

Revista Árvore, Viçosa-MG, v.37, n.6, p.1145-1152, 2013 


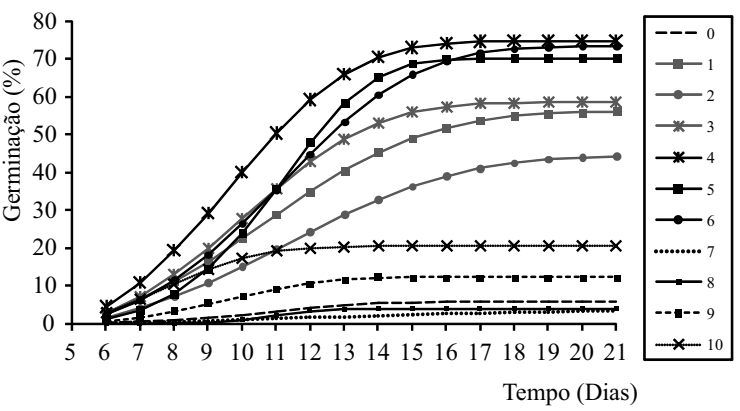

Figura 1 - Porcentagens de germinação acumulada de sementes de Delonix regia submetidas a diferentes tratamentos para superação da dormência. Tratamentos: Trat 0 - testemunha; Trat 1 - imersão em água fervente por $1 \mathrm{~min}$; Trat 2 - imersão em água a $80^{\circ} \mathrm{C}$ por 1 min; Trat 3 - imersão em água a $80^{\circ} \mathrm{C}$ por 3 min; Trat 4 - imersão em água a $90^{\circ} \mathrm{C}$ por 1 min; Trat 5 - imersão em água a $90^{\circ} \mathrm{C}$ por $3 \mathrm{~min}$; Trat 6 - escarificação manual com lixa; Trat 7 - imersão em ácido sulfúrico por 15 min; Trat 8 - imersão em ácido sulfúrico por 30 min; Trat 8 - imersão em ácido sulfúrico por 45 min; e Trat 9 - imersão em ácido sulfúrico por 60 min.

Figure 1 - Accumulated germination percentage of Delonix regia seeds submitted to different treatments to overcome dormancy. Treatments: Trat 0 - control; Trat 1 - immersion in boiling water for one minute; Trat 2 - immersion in water at $80^{\circ} \mathrm{C}$ for one minute; Trat 3 - immersion in water at $80^{\circ} \mathrm{C}$ for three minutes; Trat 4 - immersion in water at $90^{\circ} \mathrm{C}$ for one minute; Trat 5 -immersion in water at $90^{\circ} \mathrm{C}$ for three minutes; Trat 6-scarification with sandpaper; Trat 7-immersion in sulfuric acid for 15 minutes; Trat 8 - immersion in sulfuric acid for 30 minutes; Trat 8 - immersion in sulfuric acid for 45 minutes and Trat 9-immersion in sulfuric acid for 60 minutes. contortisiliquum, Bixa orellana e Adenanther apavonina, respectivamente.

A Figura 2 ilustra as porcentagens médias de germinação e o IVG das sementes, submetido aos tratamentos de imersão em água quente a $90{ }^{\circ} \mathrm{C}$ por 1 min e de escarificação manual com lixa, nas temperaturas constantes de 25 e $30^{\circ} \mathrm{C}$. Os valores médios encontrados em $30^{\circ} \mathrm{C}$ foram estatisticamente inferiores aos obtidos na temperatura de $25^{\circ} \mathrm{C}$, o que sugere que o aumento da temperatura ocasionou retardo na germinação das sementes.

As plântulas normais de flamboyant ao $12^{\circ}$ dia após a semeadura estão representadas na Figura 3A. De acordo com a ilustração da morfologia dessas plântulas, todas representam as estruturas indicadas na Figura 3B, quais sejam: cotilédones parcialmente abertos, hipocótilo, raízes secundárias curtas e raiz primária bem desenvolvida. Na Figura 3C estão ilustradas as plântulas consideradas anormais. Os principais tipos de anormalidades encontradas nos diferentes tratamentos foram: raiz primária com geotropismo negativo (Figura 3C (I)), raiz primária atrofiada (Figura 3C (II)), ausência de raízes secundárias (Figura 3C (III)), raiz primária e hipocótilo retorcidos (Figura 3C (IV)), hipocótilo desproporcional às demais estruturas da plântula, raiz primária retorcida e ausência de raízes secundárias (BRASIL, 2009).

Além das anormalidades citadas, na utilização de escarificação manual com lixa também foi observada a permanência do tegumento aderido aos cotilédones,

Tabela 1 - Porcentagem média de plântulas normais, anormais, sementes duras e sementes mortas e Índice de Velocidade de Germinação (IVG), obtidos no teste de germinação de sementes de Delonix regia submetidas a tratamentos para superação da dormência.

Table 1 - Average percentage of normal and abnormal seedlings, hard seeds and dead seeds, and Germination Speed Index (IVG) obtained in the germination test of seeds of Delonix regia submitted to treatments to overcome dormancy.

\begin{tabular}{|c|c|c|c|c|c|}
\hline Tratamento & $\begin{array}{c}\text { Plântulas } \\
\text { normais }\end{array}$ & $\begin{array}{l}\text { Plântulas } \\
\text { anormais }\end{array}$ & $\begin{array}{c}\text { Sementes } \\
\text { duras }\end{array}$ & $\begin{array}{c}\text { Sementes } \\
\text { mortas }\end{array}$ & IVG \\
\hline Testemunha & $5 \mathrm{~d}$ & 0 & 90 & 5 & $0,48 \mathrm{~d}$ \\
\hline Água fervente por $1 \mathrm{~min}$ & $60 \mathrm{ab}$ & 8 & 5 & 27 & 5,63 bcd \\
\hline Água a $80^{\circ} \mathrm{C}$ por $1 \mathrm{~min}$ & $47 \mathrm{bc}$ & 2 & 41 & 10 & 3,96 bcd \\
\hline Água a $80^{\circ} \mathrm{C}$ por $3 \mathrm{~min}$ & $62 \mathrm{ab}$ & 4 & 12 & 22 & 5,99 bcd \\
\hline Água a $90{ }^{\circ} \mathrm{C}$ por $1 \mathrm{~min}$ & 80 a & 1 & 3 & 16 & 8,02 a \\
\hline Água a $90{ }^{\circ} \mathrm{C}$ por $3 \mathrm{~min}$ & $71 \mathrm{ab}$ & 1 & 9 & 19 & 6,50 bc \\
\hline Escarificação com lixa número 80 & 76 a & 10 & 7 & 7 & 6,91 bc \\
\hline $\mathrm{H}_{2} \mathrm{SO}_{4}$ por $15 \mathrm{~min}$ & $4 \mathrm{~d}$ & 2 & 88 & 6 & $0,35 \mathrm{~d}$ \\
\hline $\mathrm{H}_{2}^{2} \mathrm{SO}_{4}$ por $30 \mathrm{~min}$ & $4 \mathrm{~d}$ & 0 & 82 & 14 & $0,36 \mathrm{~d}$ \\
\hline $\mathrm{H}_{2} \mathrm{SO}_{4}$ por $45 \mathrm{~min}$ & $13 \mathrm{~d}$ & 2 & 70 & 15 & $1,44 \mathrm{~d}$ \\
\hline $\mathrm{H}_{2}^{2} \mathrm{SO}_{4}$ por $60 \mathrm{~min}$ & $25 \mathrm{~cd}$ & 0 & 70 & 5 & $3,14 \mathrm{~cd}$ \\
\hline
\end{tabular}

Médias seguidas por pelo menos uma mesma letra nas colunas não diferem entre si, a 5\% de probabilidade de erro, pelo teste de Tukey.

Revista Árvore, Viçosa-MG, v.37, n.6, p.1145-1152, 2013 
o que provavelmente dificultou o desenvolvimento das plântulas, o que se pode interpretar como anormalidade específica para a espécie em estudo (Figura 4A). Como o tegumento constitui barreira física à entrada de água na semente, a escarificação em apenas um dos lados da semente prejudica a germinação normal das sementes, enquanto os tratamentos de imersão em água quente atuam em toda a extensão do tegumento. Além disso, as plântulas apresentaram-se estioladas e com raízes retorcidas no tratamento com lixa, conforme ilustrado
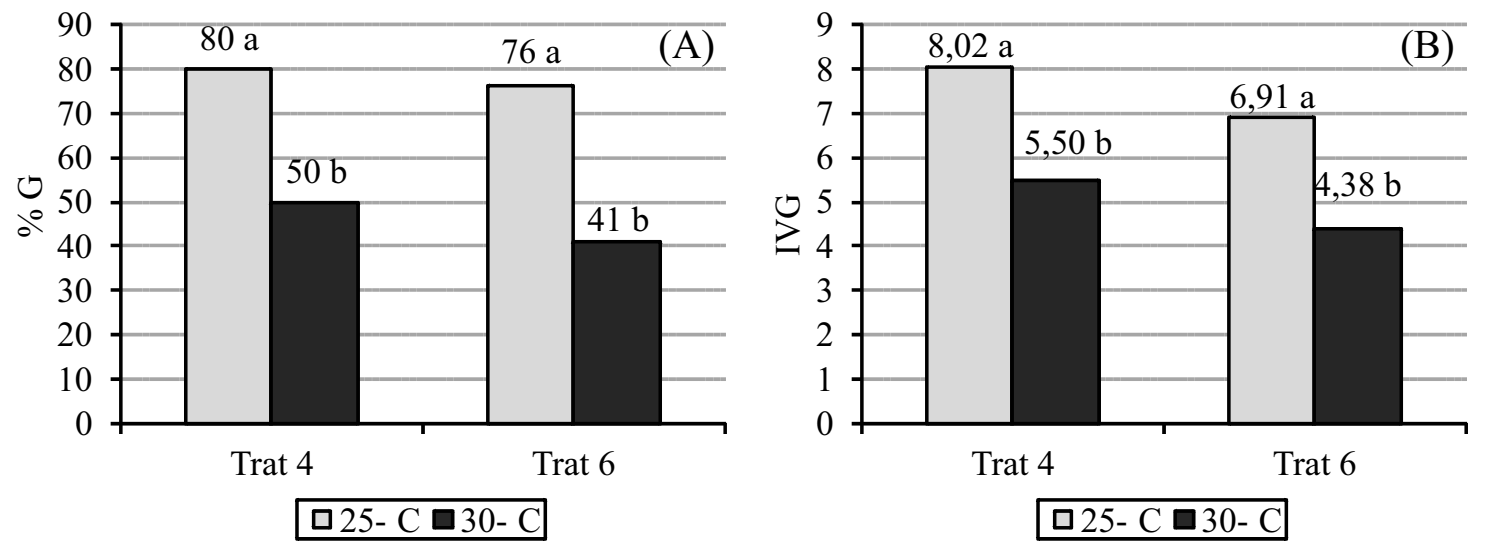

Figura 2 - Porcentagem média de germinação (\% G) (A) e Índice de Velocidade de Germinação (IVG) (B) de sementes de Delonix regia submetidas a dois tratamentos de superação da dormência: imersão em água a $90^{\circ} \mathrm{C}$ por 1 min (Trat 4) e escarificação com lixa número 80 (Trat 6), nas temperaturas de 25 e $30^{\circ} \mathrm{C}$.

Figure 2 - Average percentage of germination (\% G) (A) and Germination Speed Index (IVG) (B) of Delonix regia seeds submitted to two treatment to overcome dormancy: immersion in water at $90^{\circ} \mathrm{C}$ for 1 min (Treatment 4 ) and scarification with sandpaper number 80 (Treatement 6) at temperatures of $25^{\circ} \mathrm{C}$ and $30^{\circ} \mathrm{C}$.
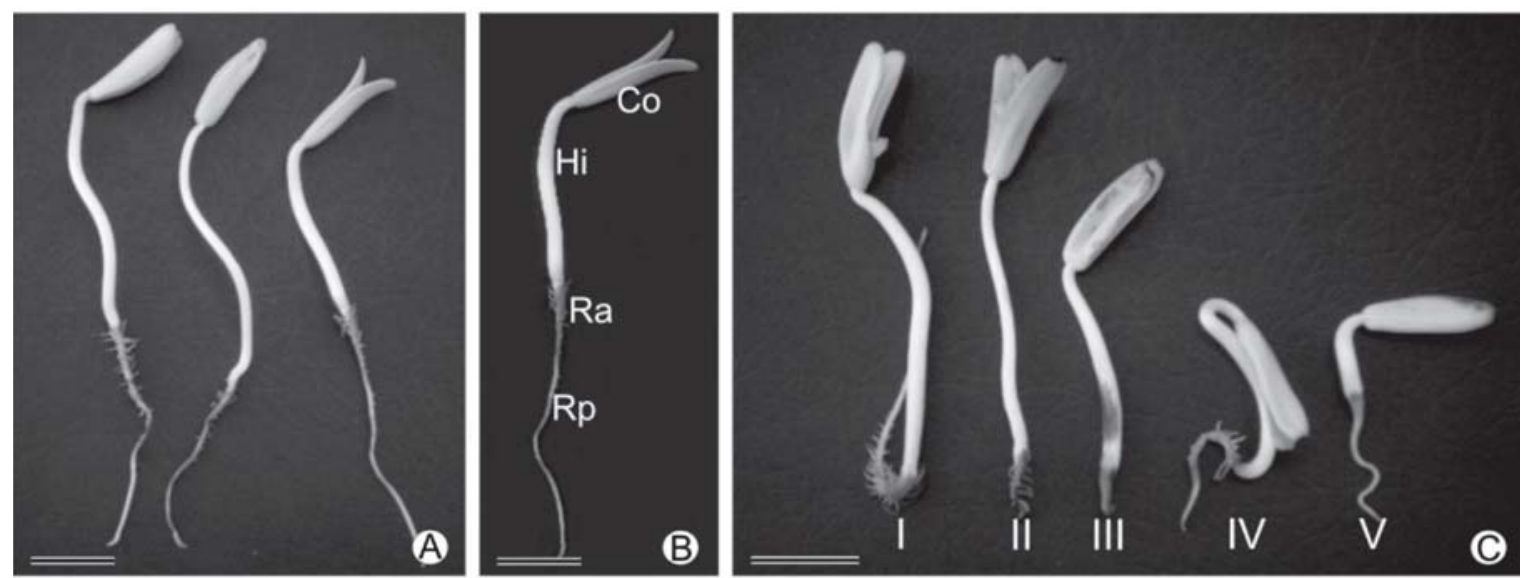

Figura 3 - Plântulas normais e anormais de Delonix regia obtidas aos 12 dias no teste de germinação: A - Plântulas normais. B - Plântula normal com cotilédones parcialmente abertos (Co), hipocótilo (Hi), raízes secundárias curtas (Ra) e raiz primária bem desenvolvida (Rp). C - Plântulas anormais com raiz primária com geotropismo negativo (I), raiz primária atrofiada (II), ausência de raízes secundárias (III), raiz primária e hipocótilo retorcido (IV) e hipocótilo desproporcional às demais estruturas da plântula (V). Barras: $2 \mathrm{~cm}$.

Figure 3 - Normal and abnormal seedlings of Delonix regia obtained on day 12 in the germination test. A - Normal seedlings. $B$ - Normal seedling with partially open cotyledons (Co), hypocotyl ( Hi), short lateral roots $(\mathrm{Ra})$ and well developed primary root ( $R p)$. C - Abnormal seedlings with primary root with negative geotropism (I), atrophied primary root (II), without secondary roots (III), primary root and twisted hypocotyl (IV) and hypocotyls disproportionate to other structures of the seedling (V). Bars: $2 \mathrm{~cm}$. 
na Figura 4A (I e II). Comparando as plântulas resultantes deste tratamento (Figura 4B (I)) com as plântulas normais dos demais tratamentos (Figura 4B (II e III)), foram observadas diferenças discrepantes nas estruturas em razão, principalmente, da presença do tegumento nas plântulas.

\section{DISCUSSÃO}

De forma geral, a superação da dormência com imersão em água quente a $90{ }^{\circ} \mathrm{C}$ por 1 min e a escarificação com lixa foram superiores à escarificação química e ao controle. Esses resultados são similares aos encontrados por Suñé e Franke (2006), em que a imersão das sementes em água aquecida e a escarificação com lixa foram eficientes para superação da dormência de Desmanthus depressus e Trifolium riograndense, respectivamente. A utilização de água quente promoveu a germinação de 15 entre as 20 sementes de leguminosas testadas por Teketay (1996),
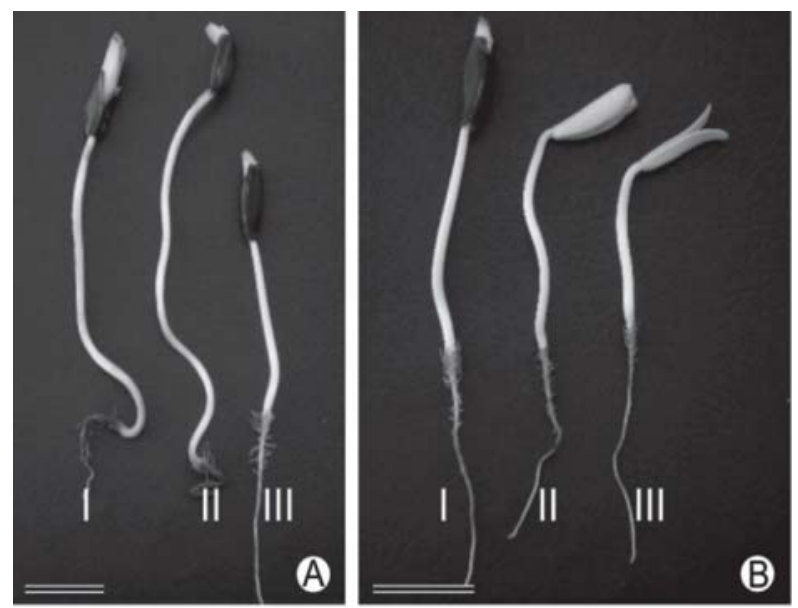

Figura 4 - Plântulas de Delonix regia obtidas no teste de germinação realizado com sementes escarificadas com lixa. A - Plântulas com permanência do tegumento aos cotilédones: estiolada (I e II) e não estiolada (III). B - Comparação entre a plântula obtida no teste de germinação com sementes escarificadas com lixa (I) e plântulas normais dos demais tratamentos (II e III). Barras: $3 \mathrm{~cm}$.

Figure 4 - Seedlings of Delonix regia obtained in the germination test conducted with sandpaper scarified seeds. A-Seedlings with integument permanence to the cotyledons, etiolated (I and II) and non-etiolated (III). B-Comparison between the seedling obtained from the germination tests with sandpaper scarified seeds (I) and normal seedlings from other treatments (II and III). Bars: $3 \mathrm{~cm}$. mostrando ser meio eficiente e prático para a superação da dormência tegumentar de sementes de algumas espécies dessa família, apesar de ter sido letal para as cinco espécies restantes.

Quando se aumentou o tempo de exposição à água quente, ocorreram decréscimos nos percentuais de germinação. Segundo Givelberg et al. (1984), exposições mais prolongadas ao calor causam alterações na viabilidade das sementes, associadas à inativação térmica ou danos ao embrião.

As sementes imersas em água a $90^{\circ} \mathrm{C}$ por $1 \mathrm{~min}$ apresentaram IVG superior aos demais, seguido pelos tratamentos de imersão em água a $90{ }^{\circ} \mathrm{C}$ por 3 min e escarificação manual com lixa. Apesar de a porcentagem final de germinação dos tratamentos com água a $90^{\circ} \mathrm{C}$ por 1 min e a escarificação manual não diferirem significativamente, a análise do IVG permite concluir que a utilização de água quente promove maior rapidez na germinação e não causa anomalias. As médias de IVG dos tratamentos com ácido não diferiram significativamente entre si e nem do controle, o que mostra que o ácido sulfúrico não foi efetivo para aumentar a velocidade de germinação.

O efeito observado da temperatura sobre a germinação pode estar relacionado aos processos bioquímicos que regulam o metabolismo necessário para iniciar o processo germinativo, afetando a porcentagem, velocidade e uniformidade de germinação das sementes (CARVALHO; NAKAGAWA, 2000). Borges e Rena (1993) consideraram a faixa de 20 a $30^{\circ} \mathrm{C}$ como a mais adequada para a germinação de grande número de espécies florestais subtropicais e tropicais. Segundo Camara et al. (2008), extremos de temperatura ambiente provocam alterações internas nas sementes, dificultando o processo germinativo e causando danos, muitas vezes, irreversíveis. Essa observação pode ser justificada pelo fato de que temperaturas altas favorecem a deterioração das sementes de algumas espécies, sendo benéficas para outras (GIACHINI et al., 2010).

Apesar de ser tratamento relativamente eficaz, a escarificação manual com lixa apresenta o inconveniente de sua aplicação prática pela dificuldade de execução em larga escala, principalmente em relação à imersão das sementes em água quente, além da permanência do tegumento nos cotilédones, conforme já indicado. Para operacionalização em maiores escalas, a alternativa é a utilização de escarificadores mecânicos, porém novos 
estudos devem ser realizados visando testar sua eficiência na superação da dormência e a presença de anormalidades nas plântulas. O tratamento de imersão em água a $90{ }^{\circ} \mathrm{C}$ por $1 \mathrm{~min}$, por sua vez, apresenta praticidade e rapidez e, em comparação com os tratamentos de imersão em ácido, não oferece perigo ao manipulador.

\section{CONCLUSÕES}

A imersão das sementes de Delonix regia em água quente $\left(90^{\circ} \mathrm{C}\right)$ por 1 min é eficiente para a superação da dormência. A escarificação manual com lixa também é eficiente nesse processo, mas prejudica o desenvolvimento das plântulas.

\section{REFERÊNCIAS}

ALVES, E. U. et al. Métodos para quebra de dormência de unidades de dispersão de ZizyphusjoazeiroMart. (Rhamnaceae). Revista Árvore, v.32, n.3, p.407-415, 2008.

AMARAL, L. I. V.; PEREIRA, M. F. A.; CORTELAZZO, A. L. Quebra de dormência em sementes de Bixaorellana. Revista

Brasileira de Fisiologia Vegetal, v.7, n.2, p.151-157, 1995.

BECHARA, F. C.; FERNANDES, G. D.; SILVEIRA, R. L. Quebra de dormência de sementes de Chamaecrista flexuosa (L.) Greene visando a restauração ecológica do Cerrado. Revista de BiologiaNeotropical, v.4, n.1, p.58-63, 2007.

BEWLEY, J. D.; BLACK, M. Physiology and biochemistry of seeds. 2.v. Berlim: SpringerVerlag, 1982.

BORGES, E. E. L.; RENA, A. B. Germinação de sementes. In: AGUIAR, I. B.; PIÑA-RODRIGUES, F. C. M.; FIGLIOLIA, M. B. (Ed.). Sementes florestais tropicais. Brasília: Abrates, 1993.

BRASIL. Ministério da Agricultura, Pecuária e Abastecimento. Regras para análise de sementes. Brasília: SDA/ACS, 2009. 399p.

BROWN, R. F.; MAYER, D. G. Representing cumulative germination 2 . The use of the Weibull Function and other empirically derived curves. Annals of Botany, v.61, p.127-138, 1988.
CAMARA, C. A. et al. Caracterização morfométrica de frutos e sementes e efeito da temperatura na germinação de Parkia pendula (Willd.) Benth. ExWalp. Ciência Florestal, v.18, n.3, p.281-290, 2008.

CARDOSO, V. J. M. Dormência: estabelecimento do processo. In: FERREIRA, A. G.; BORGHETTI, F. (Org.). Germinação: do básico ao aplicado. Porto Alegre: Artmed, 2004.

CARVALHO, N. M.; NAKAGAWA, J. Sementes: ciência, tecnologia e produção. 4.ed. Jaboticabal: Funep, 2000.

COSTA, P. A. et al. Quebra de dormência em sementes de AdenantherapavoninaL. Pesquisa Agropecuária Tropical, v.40, n.1, p.83-88, 2010.

EIRA, M. T. S.; FREITAS, R. W. A.; MELLO, C. M. C. Superação da dormência de sementes de Enterolobiumcontortisiliquum(VELL.) Morong. Leguminosae. Revista Brasileira de Sementes, v.15, n.2, p.177-181, 1993.

FERRARESI, D. A.; YAMASHITA, O. M.; CARVALHO, M. A. C. Superação da dormência e qualidade de luz na germinação de sementes de Murdannianudiflora (L.) Brenans. Revista Brasileira de Sementes, v.31, n.4, p.126-132, 2009.

GIACHINI, R. M. et al. Influência da escarificação e da temperatura sobre a germinação de sementes de Samanea tubulosa (Benth.) Barneby\& J.W. Grimes (sete cascas). Acta Amazonica, v.40, n.1, p.75-80, 2010.

GIVELBERG, A.; HORROWITZ, M.; POLJAKOFF-MAYBER, A. Germination behaviour of Solanumnigrum seeds.Journal of Experimental Botany, v.35, n.4, p.588-598, 1984.

LANG, G. A. Plant dormancy: physiology, biochemistry and molecular biology. London: CAB International, 1996. 386p.

LEMOS FILHO, J. P. et al. Germinação de sementes de Senna macranthera, Senna multijuga e Stryphnodendronpolyphyllum. Pesquisa Agropecuária Brasileira, v.32, n.4, p.357-361, 1997.

Revista Árvore, Viçosa-MG, v.37, n.6, p.1145-1152, 2013 
LUCENA, A. M. A. et al. Emprego de substratos irrigados com água de abastecimento e residuária na propagação do flamboyant. Revista de Biologia e Ciências da Terra, v.6, n.1, p.115-121, 2006.

MAGUIRE, J. D. Speed of germination: aid in selection and evaluating for seedling emergence and vigour. Crop Science, v.2, n.1, p.176-177, 1962.

MALAVASI, U. C.; MALAVASI, M. M. Dormancy breaking and germination of

Enterolobiumcontortisiliquum(Vell.)Morong seed.

Brazilian Archives of Biology and

Technology, v.47, n.6, p.851-854, 2004.

MESCHEDE, D. K. et al.Tratamentos para superação da dormência das sementes de capim braquiária cultivar marandu. Revista Brasileira de Sementes, v.26, n.1, p.76-81, 2004.

POPINIGIS, F. Fisiologia da semente. 2.ed. Brasília: ABRATES, 1985. 298p.

ROLSTON, M. P. Water impermeable seed dormancy. The Botanical Review, v.44, n.3, p.365-396, 1978.

SANTARÉM, E. R.; AQUILA, M. E. A. Influência de métodos de superação de dormência e do armazenamento na germinação de sementes de Senna macanthera (Colladon) Irwin \&Barneby (Leguminosae). Revista Brasileira de Sementes, v.17, n.2, p.205-209, 1995.
SMIDERLE, O. J.; MOURÃO JUNIOR, M.; SOUSA, R. C. P. Tratamentos prégerminativos em sementes de acácia.

Revista Brasileira de Sementes, v.27, n.1, p.78-85, 2005.

STATSOFT INC. Statistica data analysis system version 8.0. Tulsa: Statsoft, 2008.

SUÑÉ, A. D.; FRANKE, L. C. Superação de dormência e metodologias para testes de germinação em sementes de TrigoliumriograndenseBurkart e DesmanthusdepressusHumb. Revista

Brasileira de Sementes, v.28, v.1, p.2936, 2006.

TEKETAY, D. Germination ecology of twelve indigenous and eight exotic multipurpose leguminous species from Ethiopia.Forest Ecology and Management, v.80, n.1/3, p.209-223, 1996.

TELES, M. M. et al. Métodos para quebra da dormência em sementes de Leucena (Leucaenaleucocephala(Lam.) de Wit.

Revista Brasileira de Zootecnia,v.29, n.2, p.387-391, 2000.

TURNER, S. R. et al. Physical dormancy in seeds of six genera of Australian Rhamnaceae. Seed Science Research, v.15, n.1, p.51-58, 2005. 